\title{
Biocompatible Hydrogel from a Green Tide-Forming Chlorophyta
}

\author{
Kenichi Kanno (Corresponding author), Kazuki Akiyoshi, Takashi Nakatsuka, Yusuke Watabe, Shintaro \\ Yukimura, Hiromitsu Ishihara, Noriyasu Shin, Yuji Kawasaki \& Daiki Yano \\ Department of Biological and Environmental Chemistry \\ Faculty of Humanity-Oriented Science and Technology, Kinki University \\ 11-6 Kayanomori, Iizukashi, Fukuoka 820-8555, Japan \\ Tel: 81-948-22-5655 E-mail: kanno@fuk.kindai.ac.jp
}

Received: January 24, 2012

Accepted: March 1, 2012 Published: April 1, 2012

doi: $10.5539 /$ jsd.v5n4p38

URL: http://dx.doi.org/10.5539/jsd.v5n4p38

\begin{abstract}
The green-tide chlorophyta Ulva contains the functional acidic polysaccharide ulvan in its cell wall. Here, we focused on the development of a novel soft material that can be used as a biocompatible ion exchanger. Combining chitosan and ulvan solutions was found to yield a hydrogel with various functions. This ulvan-chitosan polyion complex gel was more stable than an alginic acid-chitosan gel under both acidic and basic conditions. However, an ulvan-chitosan gel-coated vessel showed only a mild effect of preventing blood clotting, whereas a heparin-chitosan gel-coated vessel prolonged clotting time. In terms of the ion-exchange behavior, the ratio of the $\mathrm{CuSO}_{4}$-concentration in $\mathrm{CuSO}_{4}$ solution treated with the gel to that in a solution without the gel showed that increasing the initial $\mathrm{CuSO}_{4}$ concentration increased $\mathrm{CuSO}_{4}$ adsorption in the gel. These studies show that this novel hydrogel can be used as an ion exchanger as well as in other applications.
\end{abstract}

Keywords: Soft material, Ulvan, Chitosan, Polyion complex, Green-tide chlorophyta, Ion exchange

\section{Introduction}

A study on the economics of ecosystems and biodiversity has revealed the importance of biodiversity for economics (Bishop et al., 2010). Wise use of biodiversity is important for sustainable development because ecosystem services are provided by biodiversity. Scientific approaches to sustainable development have been reported in various fields such as nature conservation (Alvarez, 2010), chemical technologies for recycling plastics (Chen, 2006), materials science (Wu et al., 2009), and education for the wise use of biodiversity (Kanno et al., 2011). At the 10th conference of the parties of the convention on biological diversity (CBD-COP10) held in Nagoya, Japan, delegates from more than 100 countries agreed on the new strategic plan of the Convention on Biological Diversity (CBD), namely, the 'The Aichi Biodiversity Targets' (Strategic Plan for 2020 and the Aichi Targets, 2010). The Strategic Plan is comprised of a shared vision, a mission, strategic goals, and 20 ambitious yet achievable targets. A study on the utilization of species that are both problematic and a resource is one of the possible ways to achieve strategic goal B of the Aichi Targets-to reduce the direct pressures on biodiversity and promote sustainable use.

For species that are both problematic (e.g., invasive) and a resource, various means have been employed to increase their utility and thereby, in some cases, to reduce their environmental impact. New Zealand used the hair of the invasive possum by mixing it with lamb's wool and angora to produce wool. Another example is that of the crab. Although not an invasive alien species, a vast amount of crab shell waste is released by the aquatic food industry, creating an environmental problem. Chitin is a polysaccharide found in crab shells, shellfish, insects, and some fungi. A number of investigations on chitin and chitosan revealed that they possessed biological activities such as anti-bacterial effects. This research added value to crab shell waste to produce novel valuable materials.

Green algae blooms, which are often referred to as "green tides" occur throughout the world. Local self-governing bodies and NGOs (non-governmental organizations) engage in removing the algal mats from mudflat because they devastate the scenery and emit a foul odor. In Fukuoka, Japan, green tides and algal mats are removed by special ships, heavy machinery, and volunteer workers (Figure 1). Algal mats are incinerated or buried in landfills in Hakata bay. The Wajiro tideland is important because it is where the black-faced spoonbill (Platalea minor), an endangered species that numbers less than 1,000 worldwide, passes the winter. Although the seaweed Ulva is a natural resource, it is also an environmental challenge because it causes algal blooms. 
Pollution and nutrient loading (e.g., of nitrogen and phosphorous) can result in an increase in seaweed growth and a resultant lack of oxygen because of rotting seaweed on the mudflats, and many animals living in the mud under the rotting Ulva suffocate (Donna et al., 1985). At the same time, Ulva is used in traditional (e.g., "seaweed soup") and frozen foods in Japan, and farmers also use it in compost. Mendo et al. reported that compost prepared with Ulva had lower total Kjeldahl nitrogen and produced maize plants with aerial biomass (Mendo et al., 2005). The chitin example described above has encouraged researchers engaged in studying Ulva. Many researchers have reported various biological activities for ulvan, a compound present in this seaweed, including anti-coagulant (Mao et al., 2009), anti-inflammatory (Leiro et al., 2010), anti-oxidant (Qi et al., 2006), immunostimulatory (Leiro et al., 2007), and anti-hyperlipidemic (Pengzhan et al., 2003) properties. A reduction in $\mathrm{CO}_{2}$ emissions, which is a high political priority implemented by international policy, can be achieved by switching from petroleum to sustainable biological resources for producing materials. In this study, we report on the preparation and properties of a novel soft material consisting of an ulvan-chitosan polyion complex possessing biocompatibility.

\section{Experiment}

\subsection{Materials and Methods}

All enzymes and polysaccharides were purchased from Wako Pure Chemical Industries, Ltd. Ulva pertusa was collected at the Wajiro mudflats in Fukuoka prefecture on October 2010. The samples were rinsed with seawater followed by pure water and subsequently dried in vacuo. Ulvan was extracted according to the hot water extraction method by using sodium chlorite (Robic et al., 2008). The extract was treated with glucoamylase and protease to remove contaminants. Further purification was accomplished by DEAE-cellulose column chromatography followed by dialysis and freeze-drying. Infrared spectra were recorded from powders in a $\mathrm{KBr}$ pellet on a Nicolet FTIR spectrometer. NMR spectra were recorded in $\mathrm{D}_{2} \mathrm{O}$ on a Varian NMR 400 spectrometer. The APTT reagent kit and normal human plasma were purchased from EIDIA Co., Ltd.

\subsection{Polyion Complex-Gel Formation}

At $80^{\circ} \mathrm{C}, 5 \mathrm{ml}$ of $1.5 \mathrm{wt} \%$ ulvan aqueous solution was added to $5 \mathrm{ml}$ of $1.5 \mathrm{wt} \%$ chitosan solution in $5 \%$ acetic acid. The mixture was stored at $20^{\circ} \mathrm{C}$ for $20 \mathrm{~h}$ to form a hydrogel. The obtained hydrogel was stored for $3 \mathrm{~h}$ in $100 \mathrm{ml}$ of water on 3 separate occasions to remove low molecular weight salts in the gel. The gel was then freeze-dried.

\subsection{Swelling of the Gel}

A hydrogel was created as described in section 2.2 but not freeze-dried. To study the effect of pH on gel swelling, the $\mathrm{pH}$ value was adjusted from 2 to 11 with $1 \mathrm{mM} \mathrm{NaOH}$ and $1 \mathrm{mM} \mathrm{HCl}$. After storing a degassed gel in the solution at $20^{\circ} \mathrm{C}$ for $20 \mathrm{~h}$, the volume of the gel was measured. As a control, the swelling of the alginic acid-chitosan polyion complex was examined at $\mathrm{pH}$ values of 2, 7, 8, and 11 the ratios of the gel volume at $\mathrm{pH} 7$ to the gel volumes at other $\mathrm{pH}$ values are shown in Figure 2.

\subsection{Activated Partial Thromboplastin Time (APTT) of Ulvan}

Activated partial thromboplastin time (APTT) coagulation assays were performed as described earlier by using citrate-treated normal human plasma (Albuquerque et al., 2004). The APTT of the gel was examined by using a gel-coated test tube. Five milliliters of 5\% chitosan solution in 5\% acetic acid were applied to the inside wall of the test tube. Next, $5 \mathrm{ml}$ of $5 \%$ ulvan aqueous solution were applied to the inside of the test tube and stored at $20^{\circ} \mathrm{C}$ for $20 \mathrm{~h}$. Afterwards, the test tube was rinsed with water. The infrared spectrum of the powdered inside wall showed peaks assigned to ulvan.

\subsection{Ion-Exchange of the Gel}

Eighty milligrams of freeze-dried gel were swelled in $5 \mathrm{ml}$ of $\mathrm{CuSO}_{4}$ solution at $20^{\circ} \mathrm{C}$ for $20 \mathrm{~h}$. The adsorption spectra of the supernatants were measured at $800 \mathrm{~nm}$. The concentrations of $\mathrm{CuSO}_{4}$ in the supernatants were determined by the calibration curve for $\mathrm{CuSO}_{4}$. The blank spectra were measured with pure water and the supernatant of the water-containing gel for $\mathrm{CuSO}_{4}$ solutions without and with the gel, respectively.

\section{Results and Discussion}

\subsection{Ulvan}

Ulvan was extracted according to the hot water extraction method by using sodium chlorite (Robic et al., 2008). Further purification was accomplished by DEAE-cellulose column chromatography. FT-IR spectra and NMR spectra suggested that the extract was ulvan. The characteristic absorptions of the sulfate group and uronic acids were identified in the FT-IR spectrum. The absorptions at $847,1259,1655$, and $3500 \mathrm{~cm}^{-1}$ were attributed to the 
$\mathrm{C}-\mathrm{O}-\mathrm{S}$ bending vibration of the sulfate group in the axial position, $\mathrm{S}=\mathrm{O}$ stretching vibration of the sulfate group, $\mathrm{C}=\mathrm{O}$ of uronic acids, and $\mathrm{OH}$ group, respectively.

\subsection{Polyion Complex-Gel Formation}

The sequence of repeating units in ulvan is composed of the disaccharides ulvanobiuronic acid 3 -sulfate $[\rightarrow 4)-\beta$-D-GlcA-( $1 \rightarrow 4)$ - $\alpha$-L-Rha $\quad 3$-sulfate- $(1 \rightarrow], \quad$ xylosylrhamnose $\quad$ sulfate $[\rightarrow 4)-\beta$-D-Xyl- $(1 \rightarrow 4)-\alpha$-L-Rha 3 -sulfate- $(1 \rightarrow]$ and $[\rightarrow 4)-\beta$-D-Xyl 2 -sulfate- $(1 \rightarrow 4)-\alpha$-L-Rha 3 -sulfate $(1 \rightarrow]$ (Lahaye, 1998). The cross-links of the gel consist of reversible ionic bonds, so that ion exchange can result in the loss of cross-links and thereby make the gel swell. As shown in Figure 2, the alginic acid-chitosan gel swelled under both acidic and basic conditions and was partially dissolved at $\mathrm{pH} 11$. In contrast, the ulvan-chitosan gel did not swell at any of the tested $\mathrm{pH}$ values, showing that this gel is more stable than the alginic acid-chitosan gel under both acidic and basic conditions. This resistance of the ulvan-chitosan gel to swelling under various $\mathrm{pH}$ conditions may be caused by the integrity of the ulvan chain. The carbonic acid and sulfate groups of ulvan form ionic cross-links with the amino groups of chitosan. Ulvan also forms a hydrogel with boron; however, the boron complex forms only at $\mathrm{pH}$ values over 9 (Lahaye et al., 1998). The ulvan-chitosan polyion complex-type gel was stable over a wide range of $\mathrm{pH}$ values. The swelling of the ulvan-chitosan and alginic acid-chitosan gels was also examined at various temperatures. The ratios of the gel volumes at various temperatures to the control volume at $20^{\circ} \mathrm{C}$ are shown in Figure 3. The ulvan-chitosan gel swelled only 1.09 times compared to the control. In addition, both the ulvan-chitosan and alginic acid-chitosan gels were stable within the temperature range of 0 to $80^{\circ} \mathrm{C}$.

\subsection{Activated Partial Thromboplastin Time (APTT) of Ulvan}

Blood coagulation is part of an important host defense mechanism termed hemostasis, and ulvan shows anticoagulant activity for all conditions tested thus far in the literature. Moreover, different types of surfaces are known to affect the clotting time of blood because interfacial adsorption is a factor in the clotting of blood plasma. Here, we focused on the biocompatibility of the ulvan-chitosan gel as a novel soft material. To examine the anticoagulant activity of the polyion complex, we prepared a polyion complex-coated vessel. For various sulfated polysaccharides, Figure 4 shows the ratio of the clotting time for the plasma with sulfated polysaccharide to that for the control plasma without sulfated polysaccharide. Three kinds of sulfated polysaccharide (heparin, fucoidan, and ulvan) shown to possess anticoagulant activity and prolong clotting time are displayed for comparison. Both the heparin-chitosan and fucoidan-chitosan gel-coated vessels prolonged clotting time by more than 18 -fold compared to the control. In contrast, the ulvan-chitosan gel-coated vessel only weakly prevented clotting. Although anti-coagulant activity is just one test for examining biocompatibility, these results suggest that the ulvan-chitosan gel may be a biocompatible soft material because it did not strongly affect the clotting time of blood.

\subsection{Ion-Exchange of the Gel}

An ion-exchanger is an important biomaterial. For instance, Christoforou et al. (1998) reported on ion-exchange beads, which have been shown to promote a variety of wound-healing responses in several model systems. We examined the ion-exchange behavior of the ulvan-chitosan gel (Figure 5). Figure 5 shows the ratio of the $\mathrm{CuSO}_{4}$ concentration for a $\mathrm{CuSO}_{4}$ solution treated with the gel to the initial $\mathrm{CuSO}_{4}$ concentration without gel treatment. Increasing the initial concentration of $\mathrm{CuSO}_{4}$ increased the adsorption of $\mathrm{CuSO}_{4}$ in the gel.

Given that ulvan contains about one carboxylic acid per repeating unit, the mol percent of the carboxylic acid groups in ulvan involving the formation of an ionic bond with the $\mathrm{Cu}$ ion is about $1.4 \%$ for $0.0140 \mathrm{M} \mathrm{CuSO}_{4}$, $4.6 \%$ for $0.00562 \mathrm{M} \mathrm{CuSO}_{4}$, and $12 \%$ for $0.00140 \mathrm{M} \mathrm{CuSO}_{4}$.

\subsection{Ulvan-Chitosan Gel as a Novel Soft Material}

Haug reported gel formation of a sulfated polysaccharide extracted from Ulva. However, at that time, gel formation of the sulfated polysaccharide required both borate and calcium ions (Haug, 1976). After some time, Lahaye et al. reported the formation of a hydrogel of ulvan with boron, although the boron complex formed only at $\mathrm{pH}$ values over 9 (Lahaye et al., 1998). Interestingly, the ulvan-chitosan polyion complex type gel was stable over a wide range of $\mathrm{pH}$ values. The reason for this may be that the polyion complex has many cross-linking groups (e.g., carboxyl groups and amino groups) in a single molecule. Although the mol percent of the carboxylic acid groups in ulvan involving the formation of an ionic bond with the $\mathrm{Cu}$ ion is low, this novel soft material possess a number of advantages and possibilities. First, this gel is prepared with only a few chemical reagents. This is in contrast to gels synthesized from petroleum, which require many kinds of pollutive reagents such as polymerization initiators and organic solvents. Second, although non-cross-linked ulvan possesses anti-coagulant activity, the ulvan-chitosan gel does not prevent blood clotting. This suggests that the gel can be 
used for biocompatible materials. Third, the gel is prepared from problematic algal mats. Fourth, it is a renewable organic material.

As reported by Sari (2008), Ulva shows good biosorption of $\mathrm{Pb}$ (II) and $\mathrm{Cd}$ (II) from aqueous solutions. Our research focused on the development of a novel soft material, in particular for a biocompatible ion-exchanger, because investigation of high value-added products accelerates the recycling of waste or utilization of problematic (but resourceful) species. As an example, an enormous amount of research on chitin and chitosan and their biological activities accelerated the utilization of crab shell waste to produce valuable materials. Although research on the utilization of Ulva is still in progress, the example of green tide waste may yield valuable materials.

\section{Conclusion}

In this study, we reported on the preparation and properties of a novel soft material consisting of an ulvan-chitosan polyion complex. Ulvan was obtained from the green-tide chlorophyta Ulva. Combining chitosan and ulvan solutions were found to yield a hydrogel with various functions. This ulvan-chitosan polyion complex gel was more stable than an alginic acid-chitosan gel under both acidic and basic conditions. An ulvan-chitosan gel-coated vessel showed only a mild effect of preventing blood clotting, whereas a heparin-chitosan gel-coated vessel prolonged clotting time. This suggests that the ulvan-chitosan gel does not significantly affect blood coagulation. The ratio of the $\mathrm{CuSO}_{4}$ concentration in a $\mathrm{CuSO}_{4}$ solution treated with the gel to that in the $\mathrm{CuSO}_{4}$ solution without the gel showed that increasing the initial $\mathrm{CuSO}_{4}$ concentration increased the adsorption of $\mathrm{CuSO}_{4}$ in the gel.

A reduction in $\mathrm{CO}_{2}$ emissions can be achieved by switching from petroleum to biological resources to produce materials. An enormous number of polymer materials including plastics, elastomers, fivers, and paints are synthesized from petroleum (e.g., a polystyrene sulfonic acid derivative as an ion-exchanger, polyacrylic acid as a superabsorbent polymer). Our studies suggest that the novel hydrogel can be used as a biocompatible ion exchanger as well as in other applications. Ulva, which is a species that is both problematic and a resource yielded the 'ulvan-chitosan gel,'-an alternative to polymer materials derived from petroleum. A study on the utilization of species that are both problematic and a resource is one possible way to achieve strategic goal B of 'The Aichi Biodiversity Targets': Reduce the direct pressures on biodiversity and promote sustainable use.

The International Union for Conservation of Nature (IUCN) has produced a list of '100 of the world's worst invasive alien species' (Lowe, S. et al., 2000). Invasive alien species that are introduced into areas outside of their natural habitats cause biodiversity loss by eliminating native species through competition, predation, or transmission of pathogens. Wakame seaweed (Undaria pinnatifida) and Kudzu (Pueraria montana var. lobata) are two of ' 100 of the world's worst invasive alien species'. However, they contain useful polysaccharide molecules and have been traditional foods in Japan. Hence, despite their insufficient utilization and current status as waste materials, some invasive alien species may not only problematic but also a resource. Identifying the biological and chemical functions of these apparent waste materials and reducing petroleum-derived material is one possible way to achieve strategic goal B of 'The Aichi Biodiversity Targets': Reduce the direct pressures on biodiversity and promote sustainable use.

\section{Acknowledgements}

The authors thank Mr. Satoru Matsumoto, Chairman of the Non-Political Organization Wetland Forum, for his support in the collection of Ulva pertusa at the Wajiro mudflats in Fukuoka prefecture on October 2010.

\section{References}

Albuquerque, I. R., Queiroz, K. C., Alves, L. G., Santos, E. A., Leite, E. L., \& Rocha, H. A. (2004). Heterofucans from Dictyota menstrualis have anticoagulant activity. Brazilian Journal of Medical and Biological Research, 37 (2), 167-71. http://dx.doi.org/10.1590/S0100-879X2004000200002

Alvarez, S. (2010). Valuing ecological restoration and recreational benefits in a mountain protected area: the case of Los Nevados National Park, Colombia. Journal of Sustainable Development, 3, 3-16. http://www.doaj.org/doaj?func $=$ openurl\&genre=article\&issn=19139063\&date=2010\&volume=3\&issue=4\&spag $\mathrm{e}=$

Bishop, J., Bertrand, N., Evison, W., Gilbert, S., Grigg, A., Hwang, L., Kallesoe, M., Vakrou, A., Lugt, C., \& Vorhies, F. (2010). TEEB-the economics of ecosystems and biodiversity report for business-executive summary. http://www.teebweb.org/Home/tabid/924/Default.aspx

Chen, C.-C. (2006). Development of a framework for sustainable uses of resources: More paper and less 
plastics? Environment International, 32 (4), 478-486. http://dx.doi.org/10.1016/j.envint.2005.11.001

Christoforou, C., Lin, X., Bennett, S., Connors, D., Skalla, W., Mustoe, T. A., Linehan, J., Arnold, F., \& Convention on Biological Diversity. (2010). Strategic Plan for 2020 and the Aichi Targets "Living in Harmony with Nature". http://www.cbd.int/doc/strategic-plan/2011-2020/Aichi-Targets-en.pdf\#search='Aichi Target'

Gruskin, E. A. (1998). Biodegradable positively charged ion exchange beads: A novel biomaterial for enhancing soft tissue repair. Journal of Biomedical Materials Research, 42 (3), 376-386. http://dx.doi.org/10.1002/(SICI)1097-4636(19981205)42:3<376::AID-JBM5>3.0.CO;2-G

Haug, A. (1976). The influence of borate and calcium on the gel formation of a sulfated polysaccharide from ulva lactuca. Acta Chemica Scandinavica 1947-1999, 30b, 562-566. http://dx.doi.org/10.3891/acta.chem.scand.30b-0562

Jonson, D. A., \& Welsh, B. L. (1985). Detrimental effects of Ulva lactuca (L.) exudates and low oxygen on estuarine crab larvae. Journal of Experimental Marin Biology and Ecology, 86 (1), 73-83. http://dx.doi.org/10.1016/0022-0981(85)90043-7

Kanno, K., Hidaka, T., Kaneko, T., Kawazumi, H., Karube, M., Kaneko, Y., Toyofuku, S., Hirayama, T., Saiki, R., Oda, Y., Nakanishi, K., Nakaishi, K., Kobori, S., \& Hayata. A. (2011). The partnership between a university and 5 schools for wise use of biodiversity. Journal of Sustainable Development, 4 (3), 94-100. http://dx.doi.org/10.5539/jsd.v4n3p94

Lahaye, M. (1998). NMR spectroscopic characterisation of oligosaccharides from two Ulva rigida ulvan samples (Ulvales, Chlorophyta) degraded by a lyase. Carbohydrate Research, 314 (1-2), 1-12. http://dx.doi.org/10.1016/S0008-6215(98)00293-6

Lahaye, M., Inzan, F., \& Vigouroux, J. (1998). NMR analysis of the chemical structure of ulvan and of ulvan-boron complex formation. Carbohydrate Research, 36 (2-3), 239-249. http://dx.doi.org/10.1016/S0144-8617(98)00026-5

Leiro, J. M., Castro, R., Arranz, J. A., \& Lamas, J. (2007). Immunomodulating activities of acidic sulphated polysaccharides obtained from the seaweed Ulva rigida C. Agardh. International Immunopharmacology, 7 (7), 879-888. http://dx.doi.org/10.1016/j.intimp.2007.02.007

Leiro, J. M., Varela, M., Piazzon, M. C., Arranz, J. A., Noya, M., \& Lamas, J. (2010). The anti-inflammatory activity of the polyphenol resveratrol may be partially related to inhibition of tumour necrosis factor- $\alpha$ (TNF- $\alpha$ ) $\begin{array}{llllll}\text { pre-mRNA } & \text { splicing. } & \text { Molecular } & \text { Immunology, } & 47 & \text { (5), }\end{array}$ http://dx.doi.org/10.1016/j.molimm.2009.10.030

Lowe, S., Browne, M., Boudjelas, S., \& De Pooter, M. (2000). 100 of the world's worst invasive alien species A selection from the global invasive species database, http://www.issg.org/pdf/publications/worst_100/english_100_worst.pdf

Mao, W., Li, H., Li, Y., Zhang, H., Qi, X., Sun, H., Chen, Y., \& Guo, S. (2009). Chemical characteristic and anticoagulant activity of the sulfated polysaccharide isolated from Monostroma latissimum (Chlorophyta). International Journal of Biological Macromolecules, $44 \quad$ (1), 70-74. http://dx.doi.org/10.1016/j.ijbiomac.2008.10.003

Mendo, T, Wosnitza, A., \& Barrantes, J. G. (2005). Utilization of seaweed Ulva sp. in Paracas bay (Peru): experimenting with compost. Journal of Applied Phycology, 18, 27-31. http://dx.doi.org/10.1007/s110811-005-9010-x

Nazari, A. G., Tahari, A., Moztarzadeh, F., Mozafari, M., \& Bahrololoom, M. E. (2011). Ion exchange behaviour of silver-doped apatite micro- and nanoparticles as antibacterial biomaterial. Micro and Nano Letters, 6 (8), 713-717. http://dx.doi.org/10.1049/mnl.2011.0381

Pengzhan, Y., Ning, L., Xiguang, L., Gefei, Z., Quanbin. Z., \& Pengcheng, L. (2003). Antihyperlipidemic effects of different molecular weight sulfated polysaccharides from Ulva pertusa (Chlorophyta). Pharmacological Research, 48 (6), 543-549. http://dx.doi.org/10.1016/S1043-6618(03)00215-9

Qi, H., Zhang, Q., Zhao, T., Hu, R., Zhang, K., \& Li, Z. (2006). In vitro antioxidant activity of acetylated and benzoylated derivatives of polysaccharide extracted from Ulva pertusa (Chlorophyta). Bioorganic \& Medicinal Chemistry Letters, 16 (9), 2441-2445. http://dx.doi.org/10.1016/j.bmcl.2006.01.076

Robic, A., Sassi, J.-F., \& Lahaye, M. (2008). Impact of stabilization treatments of the green seaweed Ulvarotundata (Chlorophyta) on the extraction yield, the physico-chemical and rheological properties of ulvan. 
Carbohydrate Polymers, 74 (3), 344-352. http://dx.doi.org/10.1016/j.carbpol.2008.02.020

Sari, A., \& Tuzen, M. (2008). Biosorption of $\mathrm{Pb}(\mathrm{II})$ and $\mathrm{Cd}(\mathrm{II})$ from aqueous solution using green alga (Ulva lactuca) biomass. Journal of Hazardous Materials, 152 (1), 302-308. http://dx.doi.org/10.1016/j.jhazmat.2007.06.097

Wu, J., Zhao, J., Du, F., \& Han, Z. (2009). Development of environmentally friendly modified Fe-PAN fibrous catalyst and its application in degradation of dye. Journal of Sustainable Development, 2, 214-220. http://www.doaj.org/doaj?func $=$ openurl\&genre $=$ article $\&$ issn $=19139063 \&$ date $=2009 \&$ volume $=2 \&$ issue $=3 \&$ spag $\mathrm{e}=$

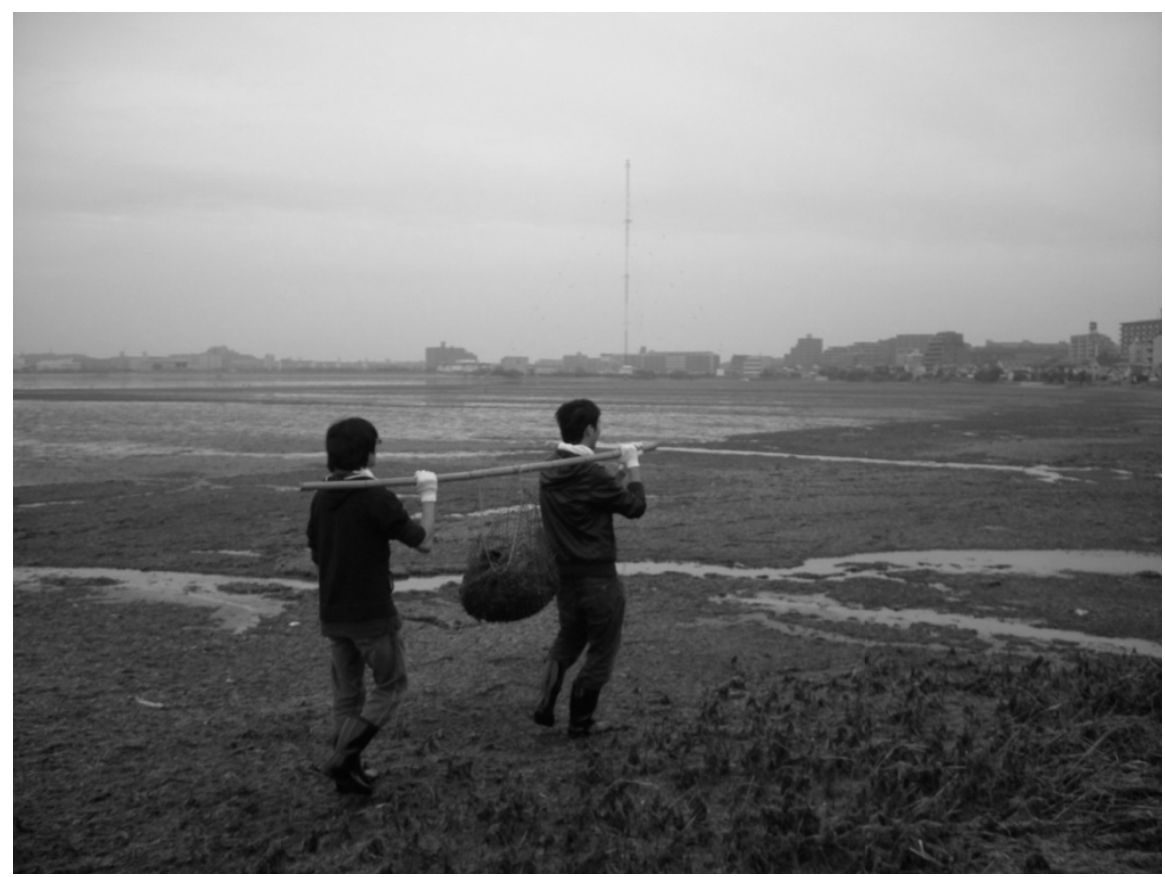

Figure 1. Civic organization removing algal mats from Wajiro mudflats

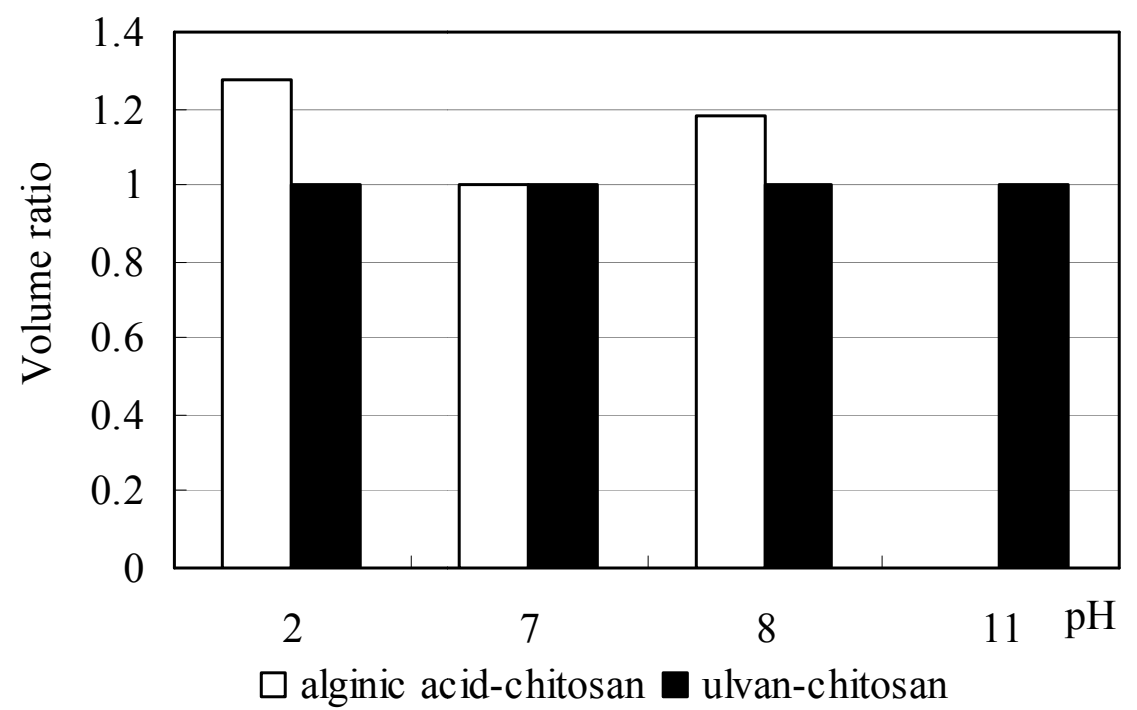

Figure 2. Swelling of ulvan-chitosan polyion complex at various $\mathrm{pH}$ values 


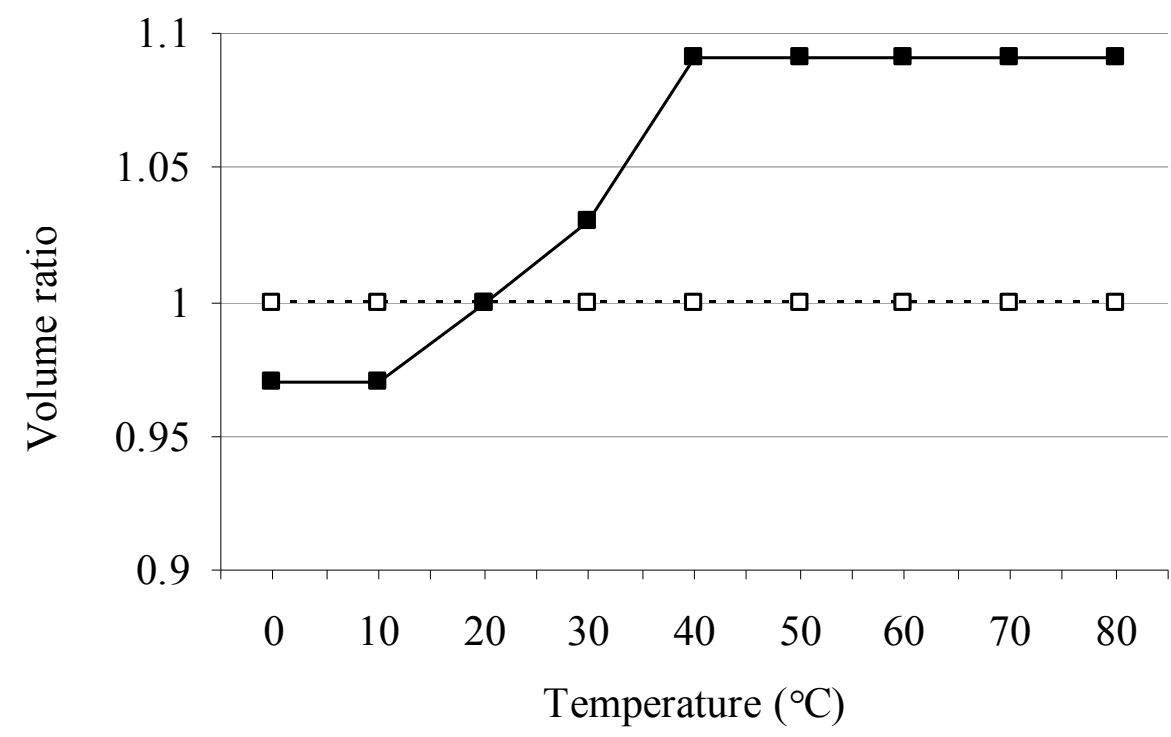

-. - - - alginic acid-chitosan $\longrightarrow$ ulvan-chitosan

Figure 3. Swelling of ulvan-chitosan polyion complex at various temperatures

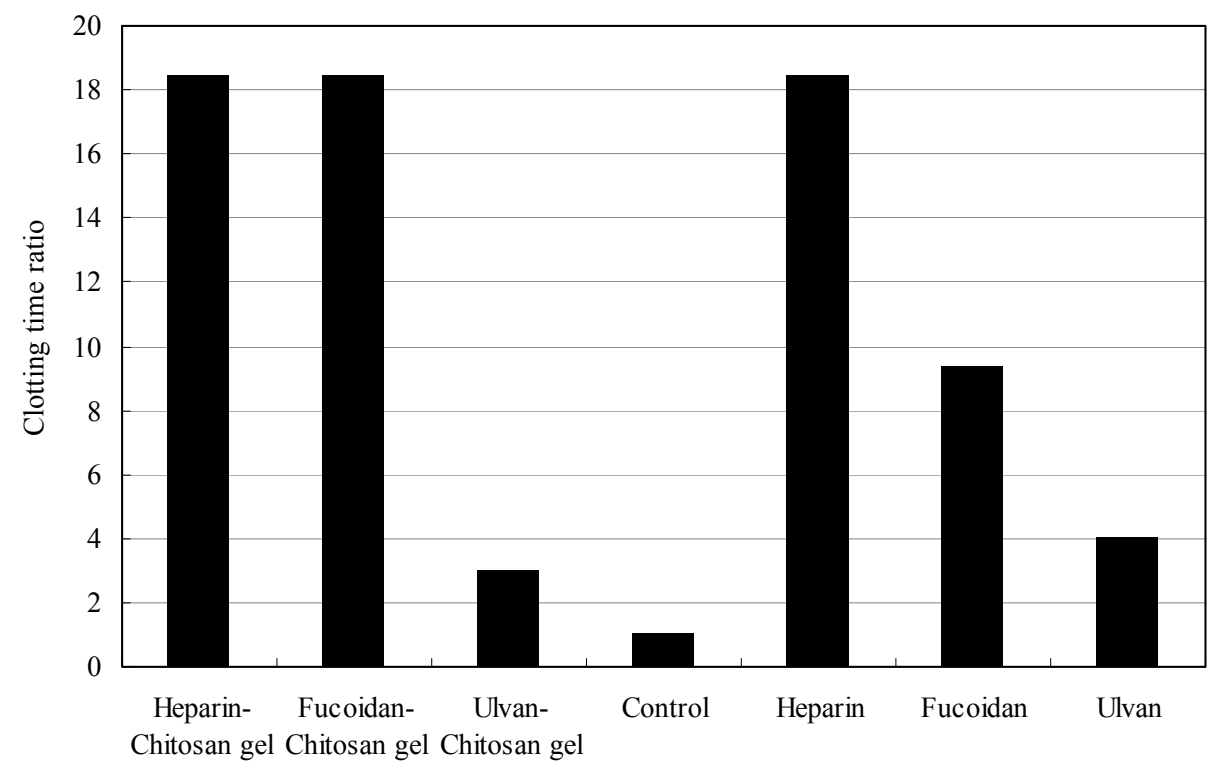

Figure 4. Anti-coagulant activity of ulvan-chitosan polyion complex 


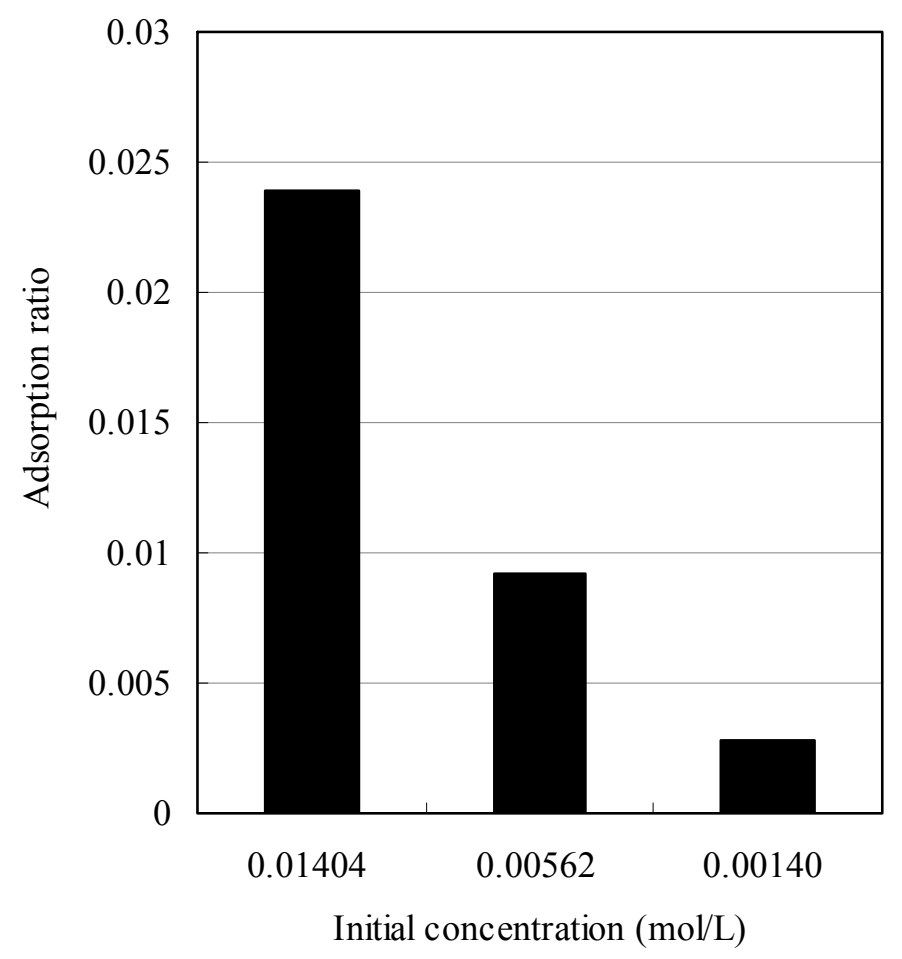

Figure 5. Adsorption of $\mathrm{Cu}$ ion in ulvan-chitosan polyion complex

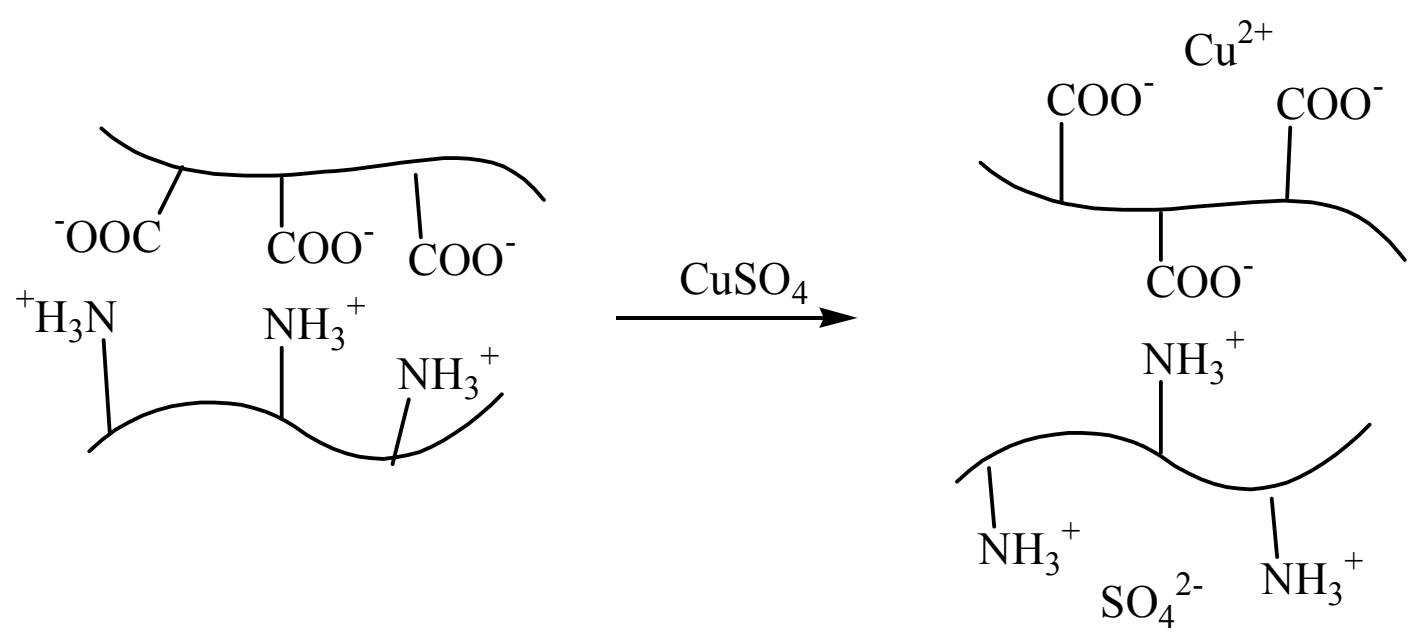

Scheme 1. Adsorption of $\mathrm{Cu}$ ion in ulvan-chitosan polyion complex 